\title{
ARTICLE
}

\section{Shutdown dose calculations for the IFMIF test facility and the high flux test module}

\author{
Keitaro Kondo $^{a^{*}}$, Frederik Arbeiter ${ }^{\mathrm{a}}$, Ulrich Fischer ${ }^{\mathrm{a}}$, Dennis Große ${ }^{\mathrm{a}}$, Volker Heinzel ${ }^{\mathrm{a}}$, Dieter Leichtle ${ }^{\mathrm{a}}$, \\ Yannick Le Tonqueze ${ }^{b}$, Martin Mittwollen ${ }^{a}$, Arkady Serikov ${ }^{a}$, Kuo Tian ${ }^{a}$ and Viktoria Weber ${ }^{a}$ \\ ${ }^{a}$ Karlsruhe Institute of Technology (KIT), Eggenstein-Leopoldshafen, 76344, Germany; ${ }^{b}$ IFMIF/EVEDA Project team, \\ Rokkasho-mura, Aomori-ken, 039-3212, Japan
}

\begin{abstract}
This work presents neutronic analyses to support the design of the test facility of the International Fusion Materials Irradiation Facility (IFMIF) in the framework of the Broader Approach activities. In order to evaluate the necessary biological shielding thickness and the reliability of remote handling tools for activated components inside the Test Cell, a detailed activation analysis has been carried out to obtain a detailed residual dose map resulting from the entire High Flux Test Module and Test Cell by utilizing the McDeLicious-11 Monte Carlo code and the mesh-tally based rigorous 2-Step approach (R2Smesh) developed at KIT. The absorbed dose rate expected at the working place of remote handling tools inside the Test Cell is approximately $100 \mathrm{~Gy} / \mathrm{h}$. A wall thickness of $150 \mathrm{~cm}$ for heavy concrete can be used as the design basis for hot cells in the test facility.
\end{abstract}

Keywords: IFMIF; fusion neutronics; Monte Carlo; shutdown dose; activation; McDeLicious; MCNP; FISPACT; R2S; McCad

\section{Introduction}

The "International Fusion Materials Irradiation Facility (IFMIF)" project is currently in the so-called "Engineering Validation and Engineering Design Activities (EVEDA)" phase which aims at producing a detailed and fully integrated engineering design of the facility under the framework of the Broader Approach activities between EU and JAPAN [1]. The "Test Facility (TF)" of IFMIF consists of several subsystems including "Test Cell (TC)", "Access Cell (AC)" and "Test Module Handling Cell (TMHC)" [2]. The TC is the central part of TF where an intensive neutron field is generated by $\mathrm{d}-\mathrm{Li}$ nuclear reactions to irradiate candidate materials placed inside the "Test Modules (TMs)" under similar conditions as expected in a future fusion power plant. The "High Flux Test Module (HFTM)" is placed just in front of the lithium target downstream of the beam and will be strongly activated as well as the target assembly. Other TMs, all other components and biological shields surrounding TC will be also highly activated. The irradiated target assembly and the HFTM need to be transported with remote handling tools to AC for maintenance works and to the TMHC for extracting the specimens from the HFTM. From the safety aspect a major concern is to assure a sufficient biological shielding and the reliability of remote handling tools, and to assess the inventory of

*Corresponding author. Email: keitaro.kondo@kit.edu radioactive nuclides produced. Detailed neutronic calculations are hence indispensable for the TC and the TMs to evaluate the radiation doses resulting from the activation of these components.

An activation analysis for HFTM was previously carried out by authors' group [3]. In this analysis only the contribution from specimens irradiated in HFTM was estimated and no detailed analysis for entire HFTM nor TC has been carried out so far. Therefore, this study has been devoted to obtain a detailed map of the radiation dose resulting from the whole HFTM and TC activated by utilizing the "Rigorous 2-Step (R2S)" approach developed at KIT [4]. The paper explains the calculation approach. Based on the results for the expected radiation doses, the shielding requirement for the maintenance and handling work in the $\mathrm{AC}$ and the TMHC is discussed.

\section{Calculation code and methodology}

Shutdown dose rate calculations were performed utilizing the Rigorous 2-Step (R2S) approach [4]. The methodological approach for the present neutronics analysis is composed of three computational steps: 1) neutron transport calculations with the McDeLicious-11 Monte Carlo code [5] using the FENDL-3, Starter Library, Release 2 (FENDL-3/SLIB2) cross-section library [6], 2) activation calculations with the FISPACT-2007 inventory code [7] and EAF-2007 activation cross-section data, and 3) decay photon 
transport calculations with the Monte Carlo code MCNP5 [8]. The R2S code system couples the above three computational steps through automated interfaces.

In the R2S approach neutron and decay photon transport calculations are performed with a same geometry model. In the present study a very detailed Monte Carlo geometry model "mdl58", which is the first reference model in the EVEDA phase prepared directly from engineering CAD data by utilizing the McCad conversion software developed at KIT [9] and includes slight improvement of the geometry representation from "mdl56" [10], was used for the in-cell components, namely, the deuterium beam ducts, the lithium target assembly with the back plate, lithium loop components and three test modules. Figure 1 shows the vertical and horizontal cuts of the present calculation model. The shape of the TC room was based on the latest TC design [11]. The biological shielding surrounding $\mathrm{TC}$ is composed of heavy concrete and a $10-\mathrm{mm}$ thick stainless steel liner is attached to the inner wall of TC.

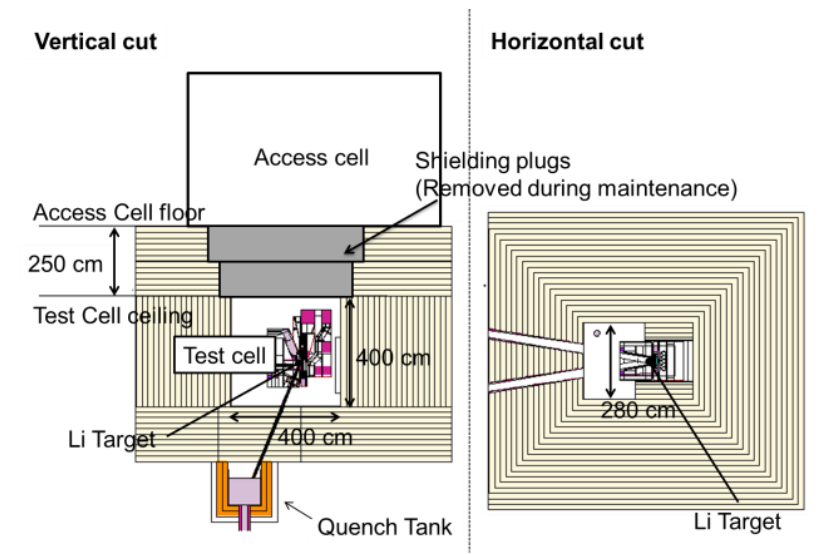

Figure 1. Vertical and horizontal cuts of the calculation model used in the present study.

Recently the R2S code system was extended utilizing mesh tally capabilities of MCNP5 [12]. In this new R2Smesh approach, the necessary neutron flux and energy distributions are obtained by using two different mesh tallies superimposed on the problem geometry. In the present analysis the first fine mesh tally with $15.6 \mathrm{M}$ meshes having $2 \times 2 \times 2 \mathrm{~cm}^{3}$ unit size was used for the neutron flux distribution. A big concern is the contribution from activated concrete and liner as well as TMs, therefore the dimension of mesh was determined so that the whole TC, liner and the inner layer of the concrete wall (at least $60 \mathrm{~cm}$ ) were covered. A second coarser mesh tally having $4 \times 20 \times 20 \mathrm{~cm}^{3}$ unit size was used to achieve better statistics for neutron energy distributions, which were in the VITAMIN-J+ 211-energy group structure with neutron energy extension up to $55 \mathrm{MeV}$. Typical neutron spectra at the target assembly and TMs can be found in Ref.5.

\section{Results and discussions}

\subsection{Calculation assumption}

According to the latest operational scenario of IFMIF, the annual campaign is made up of a 345-days irradiation period and a 20-days maintenance period (a short maintenance for 3 days is possibly included but not considered in the present study). The target assembly and HFTM will be replaced every year, while the liner, the biological shielding and other TMs may be used for more than 1 year although their exact lifetimes are not clear at this moment. In the present study the radiation dose rate after 345-day full power operation (deuteron beam injections with $40 \mathrm{MeV}, 125 \mathrm{~mA} \times 2$ with $20 \times 5$ $\mathrm{cm}^{2}$ footprint) has been assessed. It was assumed in the present analysis that the TC inside was not filled with any gas during operation and thus atmosphere activation was not considered. The distance between the back plate of the target and HFTM was $1 \mathrm{~mm}$ in the present analysis, although $2 \pm 1 \mathrm{~mm}$ is the latest design value. From the safety point of view this assumption gives more conservative estimation.

\subsection{Shutdown dose for Test Cell}

In order to assess the radiation dose absorbed to remote handling tools at their working environment, the dose absorbed by water was calculated as an indicator. According to the latest plan of the 20-days maintenance period, on the next day of the shutdown the shielding plugs above TC shown in Figure 1 are supposed to be removed and then maintenance works inside TC will start. To simulate this situation, the shielding plugs were included in the neutron transport calculation (Step 1), but removed in the photon transport calculation (Step 3) and decay photons were not generated in the shielding plug regions. To estimate a possible maximum dose rate, the dose map with 1-day (24-hours) cooling after shutdown has been evaluated. The vertical cut of the dose map obtained at the center of the beam footprint is shown in Figure 2. The major nuclides contributed to the dose are ${ }^{56} \mathrm{Mn}\left(\mathrm{T}_{1 / 2}=2.6\right.$ hours $),{ }^{58} \mathrm{Co}\left(\mathrm{T}_{1 / 2}=71\right.$ days $)$ and ${ }^{54} \mathrm{Mn}\left(\mathrm{T}_{1 / 2}=312\right.$ days). After decaying of ${ }^{56} \mathrm{Mn}$, the dose level becomes almost constant for around 100 days. The ambient dose above the opened TC will be quite high; more than $1 \mathrm{~Gy} / \mathrm{h}$, hence it is clear that no personnel can access there. The residual dose rate at the working place of remote handling tools is approximately $100 \mathrm{~Gy} / \mathrm{h}$. In the preliminary design of the remote handling tools a maximum gamma dose of $1000 \mathrm{~Gy} / \mathrm{h}$ and integral gamma dose resistance of 1 MGy have been assumed [13], and therefore the above estimated value is acceptable.

Figure $\mathbf{3}$ is the vertical cut of the dose rate distribution for opened TC at the same position but for the case that all in-cell components activated have been removed after the irradiation. Because of the activation of the liner and the concrete wall, the residual dose rate is still not small compared to Fig.2. Such a condition should be taken into account to plan the maintenance 
strategy for the liner and the biological shielding. This result suggests that further analyses would be needed on activation of them irradiated for more than 1 year.

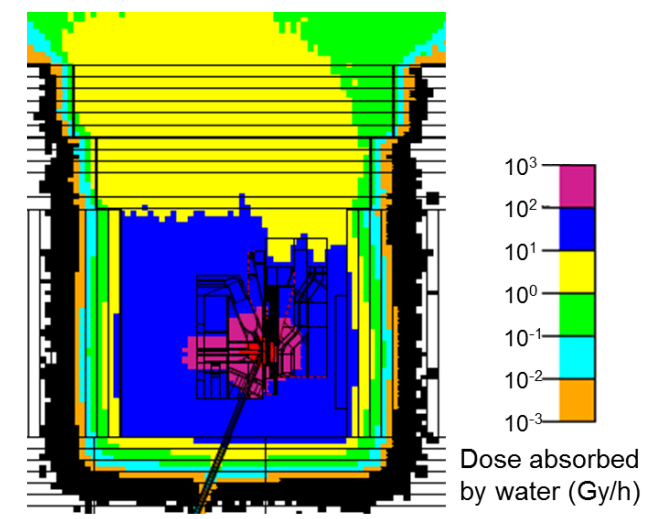

Figure 2. Vertical cut of dose rate distribution absorbed by water for opened Test Cell with all in-cell components (1 day after shutdown, 345 days operation). The black area corresponds to less $10^{-3} \mathrm{~Gy} / \mathrm{h}$.

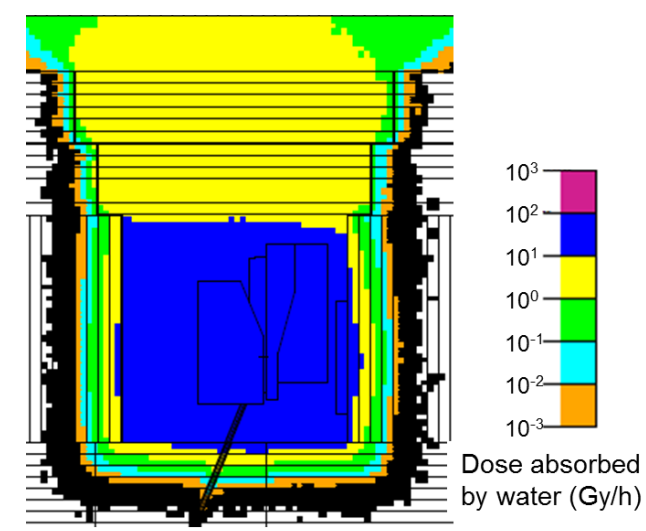

Figure 3. Vertical cut of dose rate distribution absorbed by water for opened Test Cell without in-cell components (1 day after shutdown, 345 days operation). The black area corresponds to less $10^{-3} \mathrm{~Gy} / \mathrm{h}$.

\subsection{Residual dose of activated components}

The dose rate distributions around activated in-cell components extracted from TC are needed to design remote handling tools and determine the necessary thickness of the biological shielding for AC and TMHC. Figure 4 shows the vertical cut of the dose rate distribution around the HFTM after irradiation and Figure 5 shows that around all the in-cell components together. Figure 4 shows the centre part just behind the $\mathrm{Li}$ target is the most activated. Figure 5 shows the maximum residual dose at the $\mathrm{Li}$ target exceeded $100 \mathrm{k}$ $\mathrm{Gy} / \mathrm{h}$. The area of the 10-100 Gy/h region (light blue) in Figure 5 seems to be smaller than that in Figure 4, but the reason is that the stacked components shield emitted gamma rays each other. It is never expected as the usual case to transport to and treat in TMHC all in-cell components (TA and three TMs) together, thus this estimate is as an ultimate emergency case like melting or adhering of some components. Based on these results from the activation calculation, the relationships between the thickness of a shielding wall around these components and a biological dose rate outside the wall were estimated. In order to carry out the most conservative estimation, a point source having an activity of the sum of all radioactive nuclides produced inside a component of interest and zero distance from the source to the inner surface of wall was assumed. The photon source spectra were given accordingly. Figures 6 and 7 show the relationships between the shielding wall thickness and the biological dose rate expected outside the wall for activated HFTM and all the in-cell components, respectively. The relationships were calculated for several different materials, i.e., ordinary concrete, heavy concrete, iron, lead and tungsten.

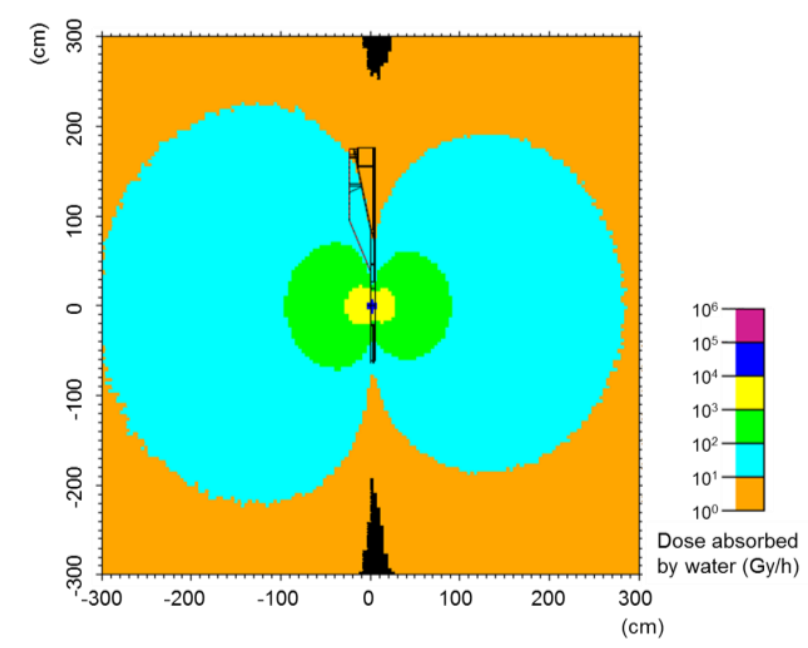

Figure 4. Vertical cut of dose rate distribution absorbed by water around HFTM (1 day after shutdown, 345 days operation). The black area corresponds to less $1 \mathrm{~Gy} / \mathrm{h}$.

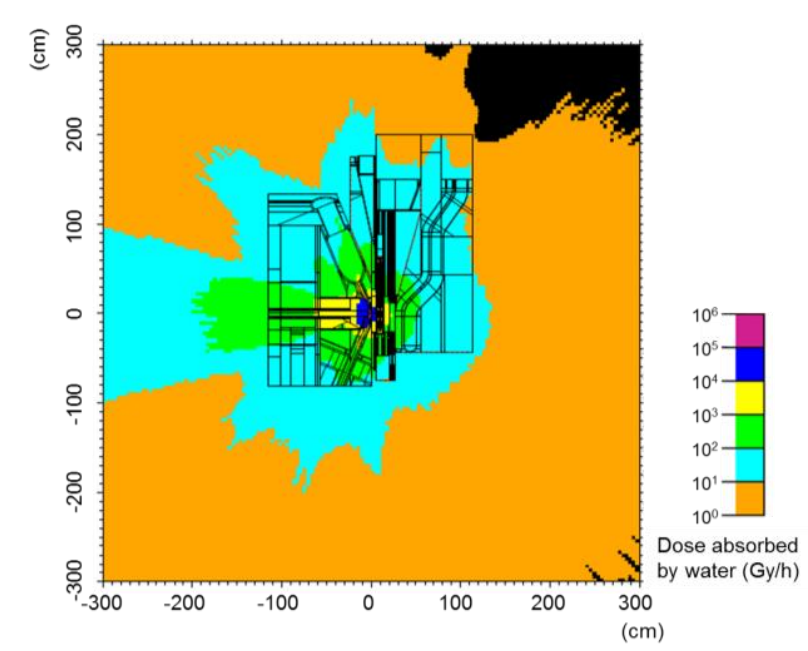

Figure 5. Vertical cut of dose rate distribution absorbed by water around all in-cell components (1 day after shutdown, 345 days operation). The black area corresponds to less $1 \mathrm{~Gy} / \mathrm{h}$.

From Figure 6 one can estimate the necessary thickness of a transport cask, for example, for activated HFTM. It is noted that this thickness should be applied for the HFTM even after specimens are removed 
because we have found that the most contributed part of HFTM to the residual dose is not specimen stacks but the outer container. Figure 7 suggests that the necessary thickness for TMHC to realize the non-limited access to outside the cell for personnel is around $130 \mathrm{~cm}$ of heavy concrete. The present design value of $150 \mathrm{~cm}$ of heavy concrete for AC and TMHC would be reasonable.

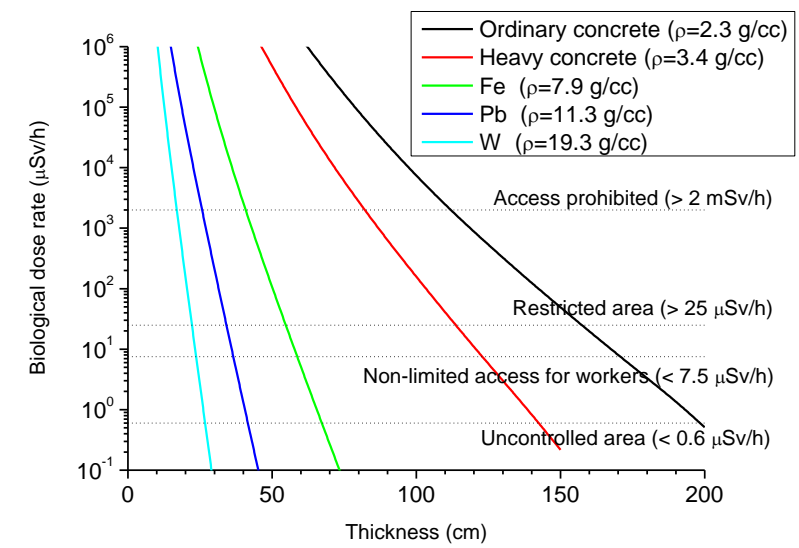

Figure 6. Relationship between shielding thickness and biological dose rate expected outside shielding for activated HFTM (1 day after shutdown, 345 days operation, point source).

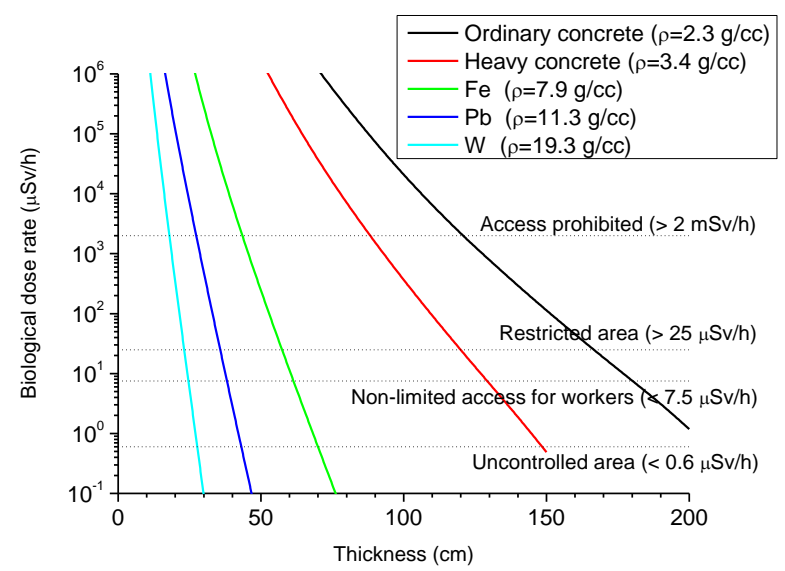

Figure 7. Relationship between shielding thickness and biological dose rate expected outside shielding for all in-cell components ( 1 day after shutdown, 345 days operation, point source).

\section{Conclusion}

The R2Smesh approach for shutdown dose calculations has been successfully extended and applied to the IFMIF application. It is demonstrated that the detailed map of the radiation dose resulting from the entire HFTM and TC activated can be calculated by using the McDeLicious code combined with the R2Smesh approach. The absorbed dose rate expected at the working place of remote handling tools inside TC is approximately $100 \mathrm{~Gy} / \mathrm{h}$. Activation of the liner and the concrete wall of TC considerably contributes to the ambient dose inside and above TC. The wall thickness of $150 \mathrm{~cm}$ for heavy concrete seems reasonable as the design basis for the AC and TMHC.

\section{Acknowledgements}

The framework project of this paper has been funded by the German Ministry for Education and Research (BMBF: Bundesministerium für Bildung und Forschung) under the grant number 03FUS0008, as a contribution to the "Broader Approach" activities. The responsibility for the contents of this publication is with the authors. This work was performed on the Helios super computer of IFERC-CSC in Rokkasho, Japan under the MCIFMIF project.

\section{References}

[1] P. Garin and M. Sugimoto, Main baseline of IFMIF/EVEDA project, Fusion Eng. Des. 84 (2009), pp. 259-264.

[2] M. Mittwollen, D. Eilert, M. Kubaschewski, V. Madzharov and K. Tian, IFMIF - Layout and arrangement of cells according to requirements of technical logistics, reliability and remote handling, Fusion Eng. Des. 87 (2012), pp. 561-564.

[3] A. Serikov, F. Arbeiter, U. Fischer, V. Heinzel, A. Klix and S.P. Simakov, Shutdown dose rate analyses for the IFMIF HFTM, Fusion Eng. Des. 86 (2011), pp. 2639-2642.

[4] Y. Chen and U. Fischer, Rigorous MCNP based shutdown dose rate calculations: computational scheme, verification calculations and applications to ITER, Fusion Eng. Des., 63-64 (2002), pp. 107-114.

[5] S. P. Simakov, U. Fischer, K. Kondo and P. Pereslavtsev, Status of the McDeLicious Approach for the D-Li Neutron Source Term Modeling in IFMIF Neutronics Calculations, Fusion Sci. Technol., 62 (2012), pp. 233-239.

[6] http://www-nds.iaea.org/fendl3/

[7] R.A. Forrest, FISPACT 2007 User Manual, Report UKAEA FUS 534, United Kingdom Atomic Energy Authority, (2007).

[8] X-5 Monte Carlo Team, MCNP-A General Monte Carlo N-Particle Transport Code, Version 5, Volume I, MCNP Overview and Theory, LA-UR-03-1987, Los Alamos National Laboratory, (2003).

[9] D. Große and H. Tsige-Tamirat, Current Status of the CAD Interface Program $\mathrm{McCad}$ for $\mathrm{MC}$ Particle Transport Calculations, Proc. $M \& C$ 2009, May 3-7, 2009, NY, USA, (2009) [CD-ROM].

[10] K. Kondo, F. Arbeiter, U. Fischer, D. Große, V. Heinzel, A. Klix, A. Serikov, K. Tian and V. Weber, Neutronic analysis for the IFMIF target and test cell using a new CAD-based geometry model, Fusion Eng. Des. 87 (2012), pp. 983-988.

[11] K. Tian, F. Arbeiter, V. Heinzel, T. Heupel, K. Kondo and M. Mittwollen, IFMIF test cell design: Current status and key components, Fusion Eng. Des., in press (2013), doi: 
10.1016/j.fusengdes.2013.03.055.

[12] M. Majerle, D. Leichtle, U. Fischer and A. Serikov, Verification and validation of the R2Smesh approach for the calculation of high resolution shutdown dose rate distributions, Fusion Eng. Des. 87 (2012), pp. 443-447.
[13] V. Queral, J. Urbón, A. García, I. Cuarental, F. Mota, G. Miccichè, A. Ibarra, D. Rapisarda and N. Casal, Preliminary definition of the remote handling system for the current IFMIF Test Facilities, Fusion Eng. Des., 86 (2011), pp. 1941-1945. 